\title{
Should Radon Counseling Wait on Evidence?
}

\author{
John G. Spangler, MD, MPH
}

(J Am Board Fam Med 2021;34:670-672.)

In this issue of the $7 A B F M$, Schwartz and colleagues ${ }^{1}$ remind family physicians of the hazards of the radioactive gas, radon, which is the second leading cause of lung cancer nationally-and the leading cause among nonsmokers. These researchers conducted a mailed survey of 350 family physicians in North Dakota (response rate of 61\%) and found that the majority of North Dakotan family doctors knew radon was radioactive. ${ }^{1}$ However, while ND's geology emits high levels of radon, most of these family doctors $(67 \%)$ do not counsel on the hazards of radon among their patients who smoke. ${ }^{1}$ While about a third of surveyed family physicians (35\%) had tested their own home for radon, only about half of these $(54 \%)^{1}$ counsel their patients on the hazards of this gas.

The recommendation to counsel patients about radon immediately raises a number of questions. First, what is the evidence that counseling increases the likelihood that patients will actually carry out radon testing? And if patients test for radon, how likely would they be to pursue mitigation, which is expensive? Does mitigation to decrease radon levels in the home actually work? And by that, I mean does mitigation reduce lung cancer mortality? Does it increase quality-adjusted life years (QALY)? Moreover, if mitigation reduces mortality, what is (are) the next counseling step(s)? Should patients who smoke be screened for lung cancer if their radon is high at home yet they otherwise do not

From the Department of Family Medicine, Wake Forest School of Medicine, Winston-Salem, NC.

Funding: None.

Conflict of interest: None.

Corresponding author: John G. Spangler, MD, MPH, Wake Forest School of Medicine, Winston-Salem, NC 27157 (E-mail: jspangle@wakehealth.edu).

\section{See Related Article on Page 602.}

qualify for low dose computed tomography screening? Should family members be screened?

Of course, these questions do not address the elephant in the room: how can we as family physicians accomplish all of the screening and health promotion that is recommended that we do?

Radon is a colorless, odorless, tasteless gas released from the radioactive decay of uranium. ${ }^{2}$ The $\alpha, \beta$, and $\gamma$ radiation it emits can cause lung cancer both in smokers and nonsmokers. Among smokers exposed to high levels of this gas, radon increases the incidence and decreases survival of lung cancer compared with smokers who are not exposed to high levels. ${ }^{2}$ Moreover, among nonsmokers, radon is the leading cause of lung cancer. ${ }^{2}$ So it is an important clinical issue if radon levels are elevated in your patients' homes.

To know if a house has radon, it must be tested using a kit that typically costs under 10 dollars. Next, to avert exposure to radon, technology must be installed to either prevent it from entering into or vent it away from the home if it is high., Notably, in newly built houses, radon's presence can be cheaply reduced by preventive construction measures. But venting this gas out of existing homes is best accomplished using fan ventilation systems. ${ }^{3-5}$ Several mitigation methods exist, but the best mitigation systems for existing homesthe so-called sub slab dispersion systems — can be pricey. ${ }^{5}$ Where I live in North Carolina, these systems cost from $\$ 1500$ to $\$ 2500$. Cheaper mitigation systems exist, but they are much less effective. ${ }^{5}$ Thus, while some families can afford effective systems, many families cannot. This leaves those families in the position of being able to test for radon's presence but unable to get rid of it. This also raises the questions of what renters should do-or even owners of town houses or condominiums, given that their housing is attached to other housing units. 
Of course, counseling on radon's hazards takes away time from other health promotion and disease prevention counseling. Furthermore, the evidence -as well as recommendations from organizations such as the US Preventive Services Task Force-is lacking. One might argue that it is so easy to simply say to patients, "You live in a high radon area and you should test your home for it." Yet even that sentence adds time to office visits to explain what radon is and to answer questions. That takes away time from other important counseling that I know can save lives. Again, what is the evidence that my counseling on radon changes patients' behavior, impacts mortality, or increases QALY?

Schmitz et al note that "several groups have studied the cost-effectiveness of radon remediation." ${ }^{1}$ They state that it is cost-effective especially if the lower-cost remediation techniques are used. But the lower-cost techniques are relatively ineffective. ${ }^{5}$ In addition, the evidence on cost-effectiveness of radon mitigation in existing homes is mixed. ${ }^{6}$ In fact, a study in the UK using QALY showed that prevention of radon exposure is cost-effective when building new homes. Unfortunately, in existing homes, mitigation is "neither cost-effective (cost per QALY) nor effective in reducing lung cancer mortality." Schmitz et al cite 1 study in which the estimated cost per QALY "in new versus remediated homes is $\$ 16,913$ versus $\sim \$ 30,000$ [which] compare[s] favorably with the costs of. . .breast cancer screening for average-risk women... estimated at \$40,135/QALY." 1 And the issue is not simply 1 of the mixed cost-effectiveness evidence for existing homes. ${ }^{6,7}$ Most patients' insurance will pay for breast cancer screening. Yet it is extremely unlikely that insurance plans would pay $\$ 1500$ to $\$ 2500$ for radon home mitigation if the gas levels were high. Nor have studies evaluated the long-term effectiveness of a mitigation system placed in the home. Is regular radon testing at some undetermined interval necessary after installation to see if the system still works? ${ }^{5}$ This might require upkeep costs.

Without third-party payers, many patients would not be able to afford mitigation. This problem corresponds with findings of a study in Wisconsin ${ }^{4}$ showing disparities in radon testing and mitigation based on race, education, poverty status, age of home, urban versus rural address, and duration of living at the residence. While radon interventions did not vary by location within the state, testing and mitigation rates were higher in more- advantaged groups. ${ }^{4}$ Can we answer how these disparities would be addressed by family physicians trying to provide regular radon counseling?

Despite (or perhaps because of) the preceding problems with radon testing and mitigation, my biggest concern regarding radon intervention is time. More precisely, opportunity costs of time. Korownyk et al reviewed the kinds of counseling, screening, and preventive interventions that make sense for family physicians to carry out. ${ }^{8}$ In brief: only those that are evidence based. Evidence is essential because if family physicians did all that was asked of them by specialty societies (at least in 2005) we would spend 11 hours on chronic care and 7 hours on prevention. Per patient. Thus, "there must be a clear understanding of opportunity costs when multiple interventions are recommended" for family doctors to carry out. ${ }^{8}$ Korownyk and colleagues, themselves family physicians, agree that "health promotion and screening [must] be provided more consistently and at lower cost by... the primary care team." But "without solid evidence of improved patient-oriented outcomes, we should not consider another intervention in primary care" ${ }^{\prime 8}$ (emphasis mine).

So in clinic, I am not sure how to prioritize counseling about high local radon levels. Schmitz et $\mathrm{al}^{1}$ recommend that I talk to patients about radon if they live in very gaseous regions, and I fully understand their concerns. Every family physician wants to cut the risk of lung cancer for his or her patients. I also think we as family physicians should be leaders in community radon education and mitigation. But when counseling most patients, even in regions rich in radon, should I wait for more evidence?

To see this article online, please go to: http://jabfm.org/content/ 34/3/670.full.

\section{References}

1. Schmitz D, Klug MG, Schwartz GG. Radon knowledge and practices among family physicians in a high radon state. J Am Board Fam Med 2021;34:602-607.

2. United States Environmental Protection Agency. Health risk of radon. https://www.epa.gov/radon/ health-risk-radon. Accessed February 24, 2021.

3. United States Environmental Protection Agency. The national radon action plan: a strategy for saving lives, 2015. https://www.epa.gov/sites/production/files/ 2019-05/documents/nrap-a_strategy_for_saving_lives__final.pdf. Accessed February 24, 2021.

4. Denu RA, Maloney J, Tomasallo CD, et al. Survey of radon testing and mitigation by Wisconsin residents, landlords, and school districts. WMJ 2019;118:169. 
5. Khan SM, Gomes J, Krewski DR. Radon interventions around the globe: a systematic review. Heliyon 2019;5:e1737.

6. Lacchia AR, Schuitema G, Banerjee A. "Following the science": in search of evidence-based policy for indoor air pollution from radon in Ireland. Sustainability 2020;12:9197.
7. Gray A, Read S, McGale P, Darby S. Lung cancer deaths from indoor radon and the cost effectiveness and potential of policies to reduce them. BMJ 2009;338:a3110.

8. Korownyk C, McCormack J, Kolber MR, Garrison S, Allan GM. Competing demands and opportunities in primary care. Can Fam Physician 2017;63:664-8. 